\title{
Mortality is higher in patients with leptomeningeal metastasis in spinal cord tumors
}

\author{
Mortalidade é mais elevada na disseminação metastática leptomeníngea em tumores da \\ medula espinhal
}

Ricardo de Amoreira Gepp', José Mauro Cardoso Couto', Maria Dorvalina da Silva², Marco Rolando Sainz Quiroga ${ }^{3}$

\begin{abstract}
Spinal cord tumors are a rare neoplasm of the central nervous system (CNS). The occurrence of metastases is related to poor prognosis. The authors analyzed one series of metastasis cases and their associated mortality. Methods: Clinical characteristics were studied in six patients with intramedullary tumors with metastases in a series of 71 surgical cases. Results: Five patients had ependymomas of which two were WHO grade III. The patient with astrocytoma had a grade II histopathological classification. Two patients required shunts for hydrocephalus. The survival curve showed a higher mortality than the general group of patients with no metastases in the CNS ( $<<0.0001)$. Conclusion: Mortality is elevated in patients with metastasis and greater than in patients with only primary lesions. The ependymomas, regardless of their degree of anaplasia, are more likely to cause metastasis than spinal cord astrocytomas.
\end{abstract}

Key words: neoplasm metastasis, spinal cord, neoplasms.

RESUMO

Tumores da medula espinhal são neoplasias raras do sistema nervoso central (SNC). A ocorrência de metástases é relacionada a pior prognóstico. Os autores analisaram uma série de casos de metástases e a mortalidade relacionada. Método: Foram estudadas as características clínicas em seis pacientes com metástases tumorais numa série de 71 casos operados. Resultados: Cinco pacientes tinham ependimomas e dois dos quais foram grau III pela classificação da OMS. O paciente portador de astrocitoma tinha classificação histopatológica de grau II. Dois pacientes necessitaram de derivação devido à hidrocefalia. A curva de sobrevivência mostrou mortalidade mais elevada no grupo de pacientes com disseminação pelo SNC (p<0,0001). Conclusão: A mortalidade, além de elevada em pacientes com metástases, é maior do que em pacientes apenas com lesão primária. Os ependimomas, independentemente do seu grau de anaplasia, costumam causar mais metástases do que os astrocitomas medulares.

Palavras-Chave: metástase neoplásica, medula espinhal, neoplasias.

Spinal cord tumors are rare neoplasias of the central nervous system(CNS), and metastases derived from these tumors occur in a minority of patients ${ }^{1}$. Ependymomas and astrocytomas are the most common spinal cord tumors, depending on the patient's age group. They correspond to more than $80 \%$ of the cases and usually present benign clinical and histological characteristics ${ }^{2,3}$. Although these tumors have been studied for many years, there are few publications about mortality or analysis of survival rates in patients with intramedullary tumors ${ }^{4,5}$. Previous studies about mortality from neoplasm of the spinal cord specifically identified the malignancy in the histopathology as being the most important predictive factor, but they did not address death due to metastatic dissemination ${ }^{4}$. Today, advancements in imaging techniques permit a complete anatomical study of the tumor's primary area, as well as the entire CNS, enabling an investigation of small satellite lesions that could significantly impact the patient's prognosis. The current literature offers only case studies about metastases of spinal cord tumors, but little is known about mortality rates due to their dissemination ${ }^{6,7}$.

We analyzed the cause of death of a series of patients diagnosed with astrocytomas and ependymomas who underwent

${ }^{1}$ Master in Science, Neurosurgeon of SARAH Network of Rehabilitation Hospitals, Brasília DF, Brazil;

${ }^{2}$ Neurophysiologist of SARAH Network of Rehabilitation Hospitals, Brasilia DF, Brazil;

${ }^{3} \mathrm{PhD}$, Neurosurgeon of SARAH Network of Rehabilitation Hospitals, Brasília DF, Brazil.

Correspondence: Ricardo de Amoreira Gepp; SQSW 300 / bloco M / apto. 204 / Sudoeste; 70673-014 Brasília DF - Brasil; E-mail: ricardogepp@zipmail.com.br / rgepp@sarah.br

Conflict of interest: There is no conflict of interest to declare.

Received 03 October 2011; Received in final form 23 July 2012; Accepted 30 July 2012 
surgery, and evaluated the importance of the metastasis in contributing to mortality. This study is based on acquired experience and presents a case series on managing metastases caused by primary tumors of the spinal cord.

\section{METHODS}

The study involved 71 patients with clinical and radiological diagnoses of spinal cord tumors who underwent surgery at our institution between August 1996 and January 2011. We describe the clinical characteristics of these patients and analyze all the cases of intramedullary tumors that had spread to the CNS. The following variables were studied: age, tumor's histology type and primary site, derivation, initial clinical symptoms, clinical classification on the McCormick scale and time lapsed until death. This study was assessed and approved by the Ethics Committee of the SARAH Network of Hospitals.

The methodology of this study involved a retrospective evaluation of patient charts to analyze the dissemination of the tumor and resultant death. All patients had been followed up by the Neurosurgery and Oncology teams of the SARAH Network.

The inclusion criteria for the study were: histological confirmation of astrocytoma or ependymoma, based on the World Health Organization's (WHO) classification criteria; presence of leptomeningeal dissemination confirmed by magnetic resonance imaging (MRI) scans; and at least one year of post-diagnosis follow-up. Patients with other histology types, short clinical follow-up or with dissemination not confirmed by neuroimaging were excluded from the study. We chose to focus on ependymomas and astrocytomas because they are the most common types of tumor with the biological tendency to spread. During this study period, we identified patients diagnosed with hemangioblastoma, intramedullary meningioma, intramedullary schwanoma, neurocytoma, ganglioglioma and melanoma. All patients were followed up until their death or until the end of the study period for a minimum of one year.

The imaging exams were independently evaluated by two different radiologists, as well as the study's corresponding author. Initially, all patients who showed clinical signs of neurological symptoms related to a tumor in an area other than the primary lesion were submitted to an MRI to investigate the region of the new symptom. After 2002, all patients with a radiological diagnosis suggestive of spinal cord ependymoma underwent MRI scans of the entire CNS for an active search of the disease (Figs 1 and 2). Patients with tumors suggestive of spinal cord astrocytoma had MRI scans of the CNS only if there were clinical signs of neurological deficits of the brain or spinal cord corresponding to an area other than the primary lesion.

The histological study of the tumor was conducted by a group of neuropathologists from the SARAH Network with an evaluation by two pathologists for further confirmation. We conducted staining for gliomas, analysis of immunohistochemical markers, electron microscopic assessment, study of mitotic indexes and investigation into the tumor's genetics. Malignant histology was defined based on WHO criteria as grade III in ependymomas and grades III and IV in astrocytomas. The statistical analysis was done on all surgical cases in order to define Kaplan-Meier general mortality curve and define the main clinical factors associated with the cause of death. The mortality curve was conducted on patients with metastatic dissemination and compared with the general mortality curve of patients with intramedullary tumors in the entire case series. The comparative statistical evaluation was run on the SPSS version 11.0 program; univariate and multivariate analyses of the deaths were also conducted.

\section{RESULTS}

The study initially evaluated a series of 71 patients, 31 with astrocytomas and 40 with ependymomas, and identified 18 deaths during the study period, $25.3 \%$ of the sample. We then investigated six patients with spinal cord tumors (Table 1) who developed intracranial metastases and compared against the total group of patients with spinal cord tumors of this series. Only the patients with astrocytomas or ependymomas were evaluated. The average age at the time of diagnosis was 18; there were four males and two females. The patient's first symptoms were associated with the primary disease of the spinal cord. The diagnosis of metastasis was made after deficits in other areas of the CNS were detected in three patients. In the other three cases, the diagnosis was made after an MRI of the spinal cord and brain. In two of these cases, the diagnosis was rendered prior to the first surgery.

Five patients had a histological diagnosis of ependymoma: one with grade III WHO classification, two with grade II and another two with grade I. The patient with the astrocytoma had a WHO classification of grade II. Five cases had the primary tumor in the thoracic region and one in the conus medullaris. The preoperative clinical evaluation showed that three patients had grade IV on the McCormick scale, one had grade III and two, grade II. Two patients required a shunt for hydrocephaly. All had surgery and complementary oncological treatment with chemotherapy and radiotherapy. Three patients died less than one year after the metastasis was discovered. One is still alive more than four years after the metastasis was discovered and another two have more than six months survival and less than two years follow-up. Additional results are described in Table 1.

Initially, the analysis of death rates was conducted on the sample of 71 cases. Univariate analysis was applied, followed by the Cox multivariate regression model (Table 2). The univariate analysis revealed that tumor resection, McCormick 
preoperative scale, tumor histology and presence of metastasis were important factors contributing to death. The multivariate analysis showed that survival was mainly influenced by the malignant histology and dissemination of the metastasis to the central nervous system ( $p=0.019)$ (Table 2). In a literature review about analysis of prognostic factors, no publications were found on metastasis and assessment of its impact on the death of patients. A general analysis of the prognostic factors for mortality revealed that malignant tumors are the most significant cause of death, with a relative risk of 8.471 ( $p=0.010)$ (Table 2).

The survival curve for the metastasis variable showed a significant statistical difference in the patients who did not have metastases (Fig 3). The cases in which there were no metastases, the average survival was 110.9 months (95\%CI 101.9-120.0). The patients without metastases of spinal cord tumors to other regions of the CNS had an average survival rate of 37.7 months (95\%CI 12.6-62.8). There was a statistically significant difference between the two groups $(\mathrm{p}<0.0001)$.

\section{DISCUSSION}

Analysis of the cause of death is one of the important results in the analysis of any oncological illness ${ }^{4,1}$. Mortality from spinal cord tumors is associated with histological characteristics, particularly the degree of malignancy and the cancer's progression to the upper levels of the spinal cord ${ }^{4,5,8}$. Previous studies on survival basically evaluated mortality in

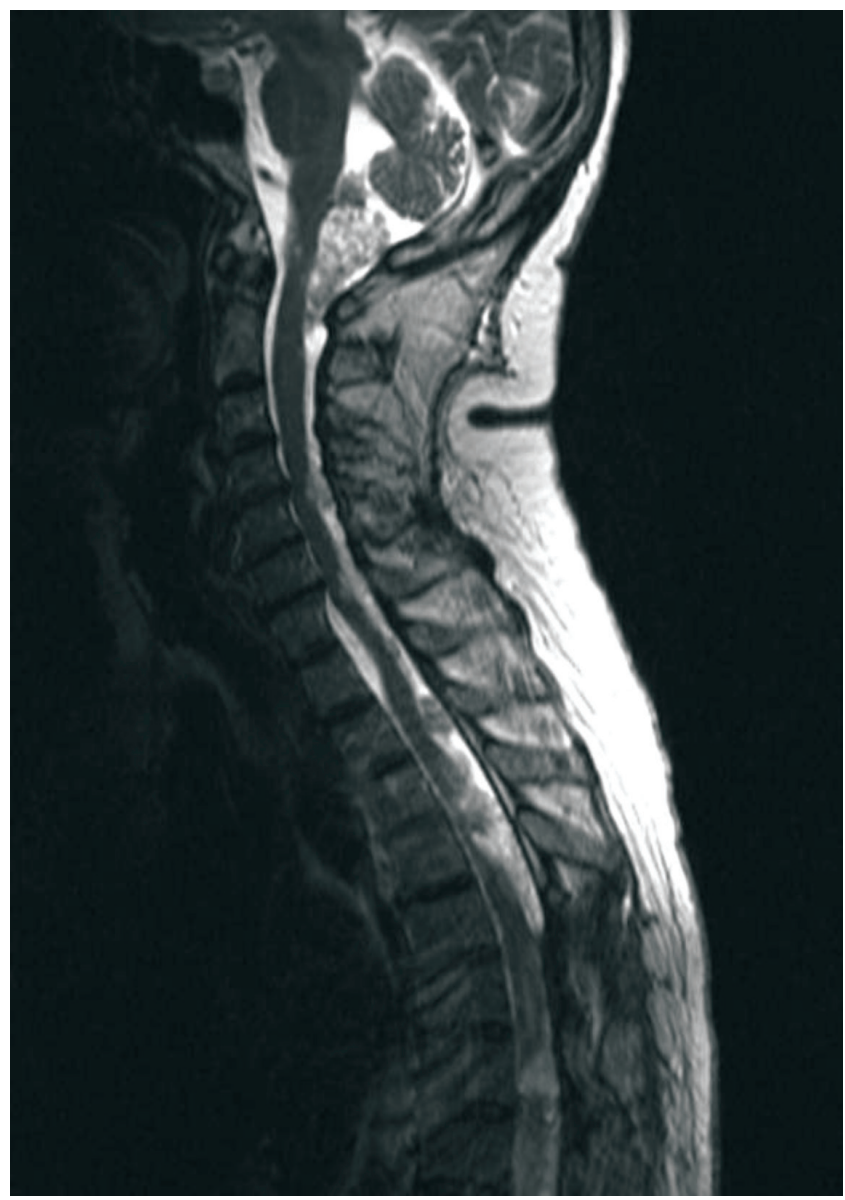

Fig 1. Sagittal T2 MRI image of the thoracic and cervical spine showing leptomeningeal spread of a primary grade II ependymoma.

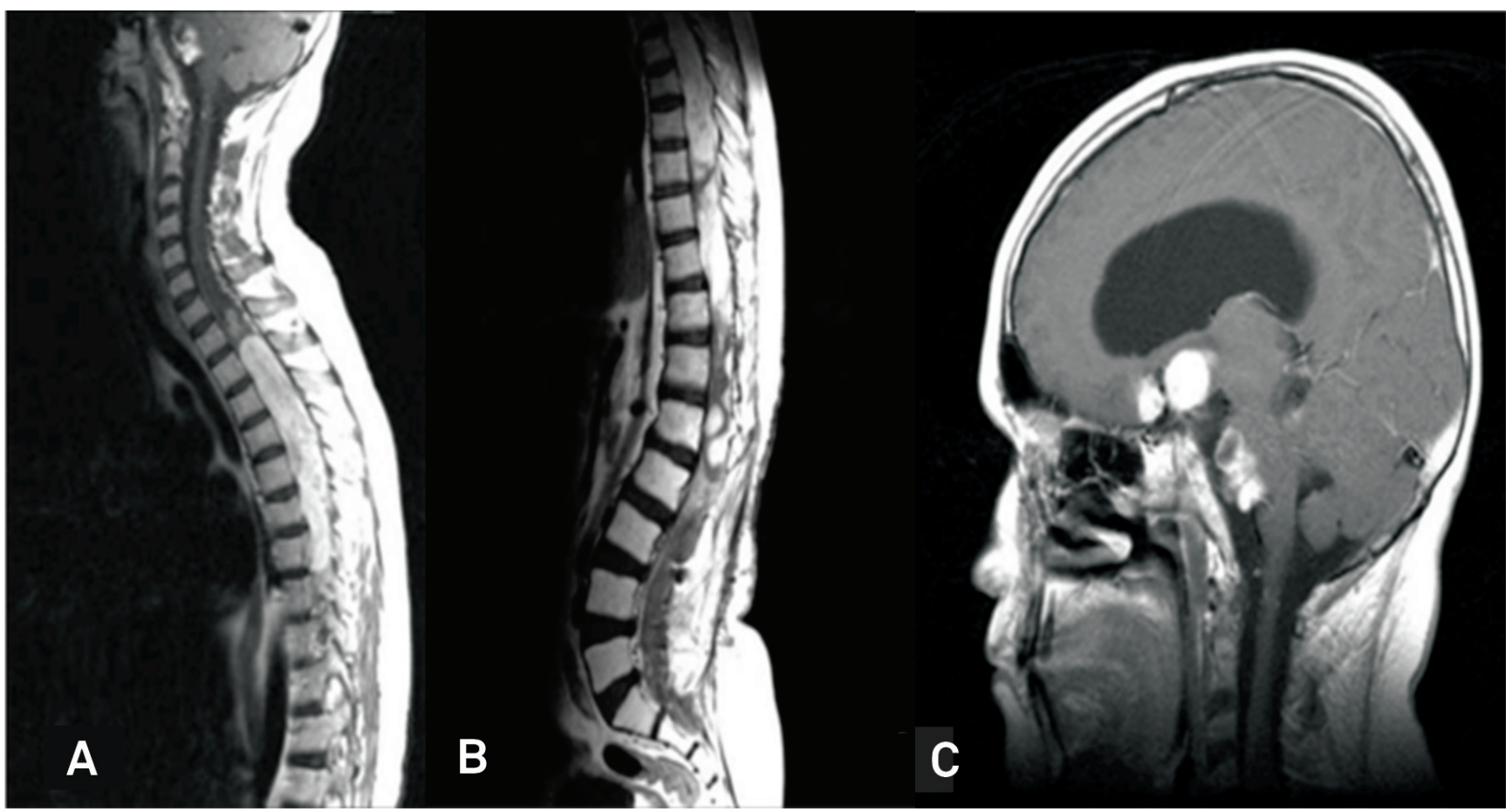

Fig 2. Brain metastasis of a grade I ependymoma. (A) Sagittal T1 with contrast Magnetic Resonance Imaging (MRI) showing primary thoracic ependymoma grade I. (B) Spinal dissemination below primary lesion. (C) Brain metastasis and associated hydrocephalus. In this case, the patient underwent radiation and a shunt for hydrocephaly. 
Table 1. Clinical aspects of the patients with metastasis.

\begin{tabular}{lccccc} 
Patient & Diagnosis & Shunt & Metastasis & Clinical features & Death \\
\hline 1 & Ependymoma grade I & Yes & Third ventricle & Headache \\
2 & Ependymoma grade III & No & Brain & Coma \\
3 & Ependymoma grade I & Yes & Brain and posterior fossa & Coma & Yes \\
4 & Astrocytoma grade II & No & Leptomeningeal dissemination & Pain & No \\
5 & Ependymoma grade II & No & Leptomeningeal dissemination & Pain \\
6 & Ependymoma grade II & No & Leptomeningeal dissemination & No \\
\hline
\end{tabular}

Table 2. Results of the Cox Regression model. Grade III and IV tumors were groups as anaplasic. The Table shows that the relative risk of death is 8.471 times higher in the group with anaplasic tumors. Metastasis is also a significant cause of death.

\begin{tabular}{lccc}
\multirow{2}{*}{ Variables } & \multicolumn{2}{c}{ Statistics } & \\
\cline { 2 - 3 } & p-value & Relative risk & $95 \% \mathrm{Cl}$ \\
Grade II & 0.282 & 2.710 & $0.381-14.668$ \\
Grade III/ IV & 0.010 & 8.471 & $1.531-42.590$ \\
Metastasis & 0.019 & 5.504 & $1.337-25.234$ \\
\hline
\end{tabular}

$\mathrm{Cl}$ : confidence interval.

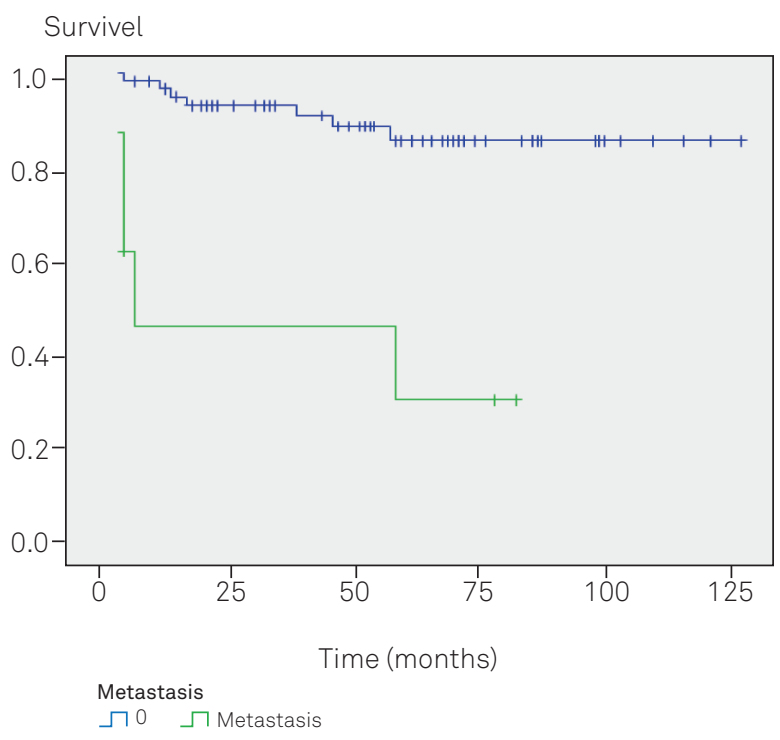

Fig 3. Kaplan-Meier curve showing the statistical difference between the group of patients with metastasis and the group without the spreading.

ependymomas and astrocytomas, since other histological types are rare and with biological peculiarities that makes it difficult to analyze them as a group ${ }^{4,5}$.

We studied the series of 71 patients to evaluate the specific cause of death secondary to the primary disease. After this initial analysis, we identified that metastasis was a significant factor and this data had not been previously described in other publications about survival in spinal cord tumors ${ }^{4,5}$. There were no deaths due to surgical complications in our study group. Surgical resection of the tumor and the patient's clinical state are important factors in treatment; however, similar to our findings in the literature, these factors were not significant in the final analysis of the causes of mortality. Studies that analyzed only the time of free disease found that the degree of surgical resection of the tumor was an important factor that contributed to a longer period of time before relapse of the primary lesion'. Two studies conducted in Brazil with adult and pediatric populations showed that surgery does not impact the patient's neurological status and that it is an important form of treatment for intramedullary tumors ${ }^{10,11}$.

A multicenter French study on spinal cord tumors, with 73 patients operated on between 1971 and 1994 showed that malignant histology (relative risk $(\mathrm{RR})=7.69$ ) and clinical time of less than four months were the most important prognostic factors associated with death $(\mathrm{RR}=4.93)^{4}$. Tseng and Tseng conducted a study with 459 patients and demonstrated that age at the time of diagnosis ( $\mathrm{RR}=2.67)$, high histology classification grade $(\mathrm{RR}=3.01)$ and types of neoplasms different from ependymomas ( $\mathrm{RR}=3.51$ ) impact mortality prognosis in patients with spinal cord tumors ${ }^{5}$.

We studied all the cases that underwent surgery at the SARAH Network and found that malignant histology $(\mathrm{RR}=8.47)$ and presence of metastasis $(\mathrm{RR}=5.50)$ were the two most important factors associated with death (Table 2). This is important information for the treatment of patients with intramedullary tumors. Since these are neoplasias of more benign characteristics, compared with brain tumors for example, there is a need for long-term follow-up and knowledge of possible causes of death in this population.

The leptomeningeal dissemination of primary tumors of the central nervous system is a very well-described phenomenon, but this is more common in neuroectodermal tu$\operatorname{mors}^{12}$. In 1906, Grund described a spinal cord tumor that extended to the subarachnoid area, and, in 1920, Rfitimeyer reported the case of a spinal cord tumor that spread to the cervix $^{12}$. Kernohan and Ody described an oligodendroglioma of the spinal cord, whose dissemination a little beyond the primary site was discovered during autopsy ${ }^{12}$. Eden reported on a patient with a lumbar spine glioma who, at the time of death, had diffuse dissemination of the cauda equine tumor to the spinal cord, filling in the basal intracranial subarachnoid spaces ${ }^{13}$.

Metastases of intramedullary tumors are rare. The presence of these lesions should be investigated by MRI of the brain and spinal cord. Mortality rates are extremely high in 
patients with metastases, as observed in this study. An important datum is that the ependymomas, regardless of having a low histology grade, are more prone to cause metastases than are astrocytomas ${ }^{7}$. Myxopapillary ependymomas are considered benign tumors (grade I) of the central nervous system with high survival rates and are likely to sustain complete resection ${ }^{7}$. Nevertheless, an aggressive course has occasionally been described and are associated with a higher incidence of metastases ${ }^{9,13}$.

One theory for the leptomeningeal metastases is the risk of dissemination during surgery. The risk of surgical contamination of the wounds with tumor cells has been a concern among surgeons. Cytological exams of cerebrospinal fluid surgery demonstrate that the operation may not be the most important factor in the dissemination of post-operative tumors for the surgeon ${ }^{14,15}$. Wilkins and Odom studied the surgery cytology of patients with craniotomies and found that surgical handling did not increase the dissemination of tumor cells ${ }^{14}$. Mavroudis, Towsend and Wilson reported a metastatizant ependymoma of cauda equine and discussed the possibility that the metastases may have been associated with the number of surgeries and the spread of ependymal cells in the subarachnoid space during the operations ${ }^{15}$. That theory does not explain our two cases that were diagnosed before any type of invasive procedure was performed ${ }^{15}$.

Metastases of spinal cord tumors caused three deaths in our patient series (Fig 1). Although there are only a few articles in the literature, Rezai et al. found disseminated lesions in the autopsy of 11 patients, without a single specific symptom $^{16}$. It is likely that with the growing advancements in MRI imaging techniques more cases of barely symptomatic metastastic dissemination will be identified. The fact that previous case series analyzed mortality and did not assess the implications of metastasis as an important contributor may be related to the fact that those studies were not able to perform an analysis by radiological means, as is possible today ${ }^{4,5}$.

In our cases, there was a predominance of ependymomas over astrocytomas. Metastasis in the case of the astrocytoma may have been associated with a malignant histology pattern, something that was not seen in the cases of ependymomas. Sarabia et al. published the description of a case of a malignant astrocytoma intracranial dissemination and discussed the fact that there are only 19 other such cases described in the literature ${ }^{17}$. Despite having been described by Mallory in 1908, metastasis of intramedullary tumors is not well documented in the literature ${ }^{17}$. Although ependymomas are, in most cases, confined tumors of low malignancy, they have a greater capacity to spread into the subarachnoid space, unlike astrocytomas ${ }^{8,18,19}$.

There is only one case report in the literature that describes the occurrence of a grade I astrocytoma that caused dissemination to the brain ${ }^{12}$. Contrary to the concept of metastasis, gliomas can originally be multicentric, presenting in various places in the CNS at the same time and able to continue between the lesions ${ }^{20}$.

Occurrence of these metastases changed the manner in which initial radiological evaluation and clinical follow-up is conducted of patients with spinal cord tumors at the SARAH Network of Rehabilitation Hospitals (Fig 2). The cases reported here had higher rates of mortality than the usual spinal cord tumors. Patients admitted with a diagnosis of spinal cord tumor are now submitted to an active investigation of possible metastatic lesions due to the severity of the situation and also because of changes in the prognosis of these patients. In these specific cases, all of the patients underwent MRIs of the entire spinal cord and brain. The same recommendation was made by Fasset et al. ${ }^{7}$ Their work demonstrated that, in pediatric patients, lesions secondary to intramedullary tumors can spread metastases throughout the whole $\mathrm{CNS}^{7}$.

In conclusion, the incidence of metastases of spinal cord tumors is uncommon. This study demonstrated that mortality in patients with intramedullary tumors that metastasized is higher, and is one of the main factors in the cause of death. A malignant astrocytoma is more likely to spread than benign tumors. Ependymomas, regardless of their degree of anaplasia, are more susceptible to causing metastasis than are astrocytomas. Despite the relative rarity of dissemination of spinal cord tumors, this manifestation of tumor growth should be considered in any patient with signs of brain disorders, medullary symptoms above the site of the original lesion or neurological deterioration after the removal of a spinal cord tumor. Mortality rates are high in patients with metastasis and greater than in patients with only primary lesions.

\section{References}

1. Epstein FJ, Farmer JP. Pediatric spinal cord tumor surgery. Neurosurg Clin N Am 1990;569-590.

2. Epstein F. Spinal cord astrocytomas of childhood. Prog Exp Tumor Res 1987;30:135-153.

3. Epstein FJ, Farmer JP, Freed D. Adult intramedullary spinal cord ependymomas: the result of surgery in 38 patients. J Neurosurg 1993;79:204-209.

4. Bouffet E, Pierre-Kahn A, Marchal JC, et al. Prognostic factors in pediatric spinal cord astrocytoma. Cancer 1998;83:2391-2399.

5. Tseng JH, Tseng MY. Survival analysis of 459 adult patients with primary spinal cancer in England and Wales: a population-based study. Surg Neurol 2007;67:53-58.

6. Abel TJ, Chowdhary A, Thapa M, et al. Spinal cord pilocytic astrocytoma with leptomeningeal dissemination to the brain. Case report and review of the literature. J Neurosurg 2006;105: 508-514.

7. Fassett DR, Pingree J, Kestle JR. The high incidence of tumor dissemination in myxopapillary ependymoma in pediatric patients. Report of five cases and review of the literature. $J$ Neurosurg 2005;102:59-64. 
8. Przybylski GJ, Albright AL, Martinez AJ. Spinal cord astrocytomas: long-term results comparing treatments in children. Childs Nerv Syst 1997;13:375-382.

9. Boström A, von Lehe M, Hartmann W, et al. Surgery for spinal cord ependymomas: outcome and prognostic factors. Neurosurgery 2011;68:302-308.

10. Taricco MA, Guirado VM, Fontes RB, Plese JP. Surgical treatment of primary intramedullary spinal cord tumors in adult patients. Arq Neuropsiquiatr 2008;66:59-63.

11. Gepp Rde A, Couto JM, Silva MD, Silva RT, Neri EA. Intramedullary tumors in children: analysis of 24 operated cases. Arq Neuropsiquiatr 2010;68:396-399.

12. Johnson DL, Schwarz S. Intracranial metastases from malignant spinal-cord astrocytoma. Case report. J Neurosurg 1987;66:621-625.

13. Plans G, Brell M, Cabiol J, Villà S, Torres A, Acebes JJ. Intracranial retrograde dissemination in filum terminale myxopapillary ependymomas. Acta Neurochir 2006;148:343-346.

14. Wilkins RH, Odom GL. Cytological changes in cerebrospinal fluid associated with resections of intracranial neoplasms. J Neurosurg 1966;25:24-34

15. Mavroudis C, Townsend JJ, Wilson CB. A metastasizing ependymoma of the cauda equina. Case report.J Neurosurg 1977;47:771-775.

16. Rezai AR, Woo HH, Lee M, Cohen H, Zagzag D, Epstein FJ. Disseminated ependymomas of the central nervous system. J Neurosurg 1996;85:618-624.

17. Sarabia M, Millán JM, Escudero L, Cabello A, Lobato RD. Intracranial seeding from an intramedullary malignant astrocytoma. Surg Neurol 1986;26:573-576.

18. Przybylski GJ, Albright AL, Martinez AJ. Spinal cord astrocytomas: long-term results comparing treatments in children. Childs Nerv Syst 1997;13:375-382.

19. Yücesoy K, Ozer E, Koyuncuoglu M. Parenchymal brain metastasis of a spinal myxopapillary ependymoma after extradural manipulation. Acta Neurochir 2001;143:1071-1072.

20. Ng HK, Leung CH, Boet R, Poon WS. Spinal cord pilocytic astrocytoma with cranial meningeal metastases. J Clin Neurosci 2001;8:374-377. 